\title{
Determination of fracture energy (mode I) in the inverse fiber metal laminates using experimental-numerical approach
}

\author{
Sz. Duda $\cdot$ M. Smolnicki $\cdot$ T. Osiecki $\cdot$ G. Lesiuk
}

Received: 25 February 2021 / Accepted: 28 June 2021 / Published online: 9 July 2021

(C) The Author(s) 2021

\begin{abstract}
Fiber metal laminates (FML) are hybrid materials consisting of metal and composite layers. They have great mechanical and fatigue properties. However, interface between metal and composite layers can be critical for their final properties. In this paper, process of determination of some fracture parameters of this interface in unusual FML material is described. Experimental tests following ASTM norm were conducted using Double Cantilever Beam (DCB). However, due to asymmetry, fracture energy cannot be obtained directly from the force-displacement curve. Finite element method simulations were carried out using cohesive elements and cohesive surfaces approach. The cohesive behavior of interface layers were modelled using traction separation law. Key properties of this law were obtained-maximal traction and fracture energy. In this particular case cohesive approach was better in reflecting
\end{abstract}

Sz. Duda · M. Smolnicki · G. Lesiuk ( $₫)$

Faculty of Mechanical Engineering, Wroclaw University

of Science and Technology, Wroclaw, Poland

e-mail: Grzegorz.Lesiuk@pwr.edu.pl

Sz. Duda

e-mail: Szymon.Duda@pwr.edu.pl

M. Smolnicki

e-mail: Michal.Smolnicki@pwr.edu.pl

T. Osiecki

Institute of Lightweight Structures, Chemnitz University

of Technology, Chemnitz, Germany

e-mail: Tomasz.Osiecki@mb.tu-chemnitz.de experimental results. Determined values can be used in later research tasks (like modelling big structures containing this material) as material properties. The presented approach can be used successfully to obtain fracture energy in cases of materials for which standard approach is insufficient.

Keywords Composite materials - Fracture resistance $\cdot$ fiber metal laminate $\cdot$ Finite element analysis - Double cantilever beam test

\section{Introduction}

Modern-day technologies drive the development of new hybrid materials. Hybrid laminates are the newest combination of different materials and are being quickly developed by top universities in the European Union (Osiecki 2020; Tomasz et al. 2017). One of the characteristic groups of hybrid laminates is Fiber Metal Laminates (FMLs) (Salve et al. 2016; Balkumar et al. 2016). The FML is a material that consists of a combination of metal layer sandwiching and fiberreinforced plastic layers (Banat et al. 2016). Their structure consists of popular metal alloys such as aluminum, magnesium, titanium alloys, and fiberreinforced composite materials based on carbon, glass, and aramid fibers (Botelho et al. 2006). Those materials have significant advantages, such as 
fatigue-resistance, superior corrosion resistance, impact resistance, and excellent mechanical properties (Carrillo and Cantwell 2009). These kinds of materials are in use in Aerospace Engineering, but the automotive industry is gradually using them expansively (Ding et al. 2021; Aksit and Altstädt 2020).

The interface between layers of composite material can be crucial in terms of a whole structure's behaviour. This is especially true in FML when neighboring layers can be drastically different materials like steel and thermoplastic. The delamination is an essential mode of failure of FML based structures. Thus, the definition of the cohesive layer in the interface region is the key to correcting real conditions. The standard approach to this problem is to use cohesive elements. However, in some applications, there is a better approach that is based on cohesive surfaces. Cohesive surfaces are defined by interactions rather than by using additional elements. Thus, the interface modelled with cohesive surfaces has zero thickness (contrary to cohesive elements interface with non-zero thickness). The main difference will be described below based on the Abaqus implementations (which will be used in this paper) (Hibbit and Sorensen 2013). However, cohesive elements give more control over stiffness and mesh density. Cohesive surfaces do not have to be bonded with each other in the initial step of analysis (which is necessary for cohesive elements). They can bond again after being debonded, which is impossible when using cohesive elements. There are a few models approaching behavior of cohesive elements such as tractionseparation law, continuum-based model, and uniaxial stress-based model. Nevertheless, it is recommended for the DCB test to use traction-separation law definition so both approaches are viable (Diehl 2005). Cohesive surfaces must use traction-separation law.

To sum up, the cohesive elements approach gives more control over simulations and more possibilities, but the cohesive surface approach can be as good as the cohesive element and often is far more effective in terms of time and complexity. For example, Soroush et al. (Soroush et al. 2018) indicate that threedimensional analysis using cohesive surfaces decreases computational significantly. A three-dimensional analysis can capture the nonlinear progression of delamination front (through the width of the specimen) (Alfano and Crisfield 2001). Examples of three-dimensional analysis of delamination can be found in Alfano and Crisfield (2001); Alfano et al. (2007); Bieniaś et al. (2017), and in Soroush et al. (2018); Alfano and Crisfield (2001) for a cohesive surface approach. In a two dimensional analysis, the crack front progression is assumed to be the same through the specimen width. However, this simplification does not have a significant influence on the results, and this approach was used with good results in Soroush et al. (2018); Ning (2015); ASTM International 2001).

The problem with analyzing FML structures is identifying material data, especially in the interface zone. The literature shows researchers dealing with this issue mostly conducting DCB tests for different types of FMLs to find out the value of Mode I interlaminar fracture toughness $\left(\mathrm{G}_{\mathrm{Ic}}\right)$ (Jimenez and Miravete 2004; Burlayenko and Sadowski 2008; Millar et al. 2014; Elices et al. 2002). Even if the specimens are nonnormative, the test is carried out according to the ASTM D5528-01 (ASTM International 2001) in terms of equipment and process parameters. Only the final value of energy shall be calculated differently. In this case, to obtain the value of the interlaminar fracture toughness, the Finite Element Method (FEM) analysis is conducted to validate the mode I interlaminar fracture toughness. This method for determination of $\mathrm{G}_{\mathrm{Ic}}$ is well-established in the literature (Elices et al. 2002; Abdel Wahab 2015; Goyal and Irizarry 2016). The unique side of this research is the innovative material, socalled inverse FML.

Furthermore, the Cohesive Zone Model (CZM) is used to approach the DCB test simulation using the FEM. The cohesive zone can be applied to modelling the fracture process in this research, the delamination process occurring in the interlaminar section ("Aerospace Aluminum Distributor Supplier" 2021; Ly et al. 2016). A cohesive law characterizes the phenomena in the cohesive zone in terms of the traction and the separation of the surfaces during the fracture process. A cohesive law is also known as a traction-separation law (Goyal and Irizarry 2016). The CZM is represented by traction ( $\sigma$-separation $(\delta$-curve-as it is schematically drawn in Fig. 1 . The shape of the traction-separation curve can vary depending on the specific model used. The most popular variant is the bilinear law (defined by maximum traction and fracture energy or fracture displacement). Other 


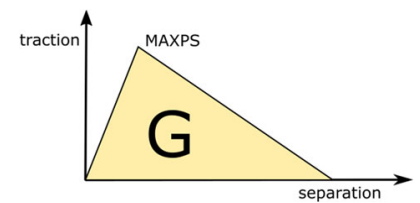

Fig. 1 Bilinear traction-separation law definition

possibilities include trapezoidal, exponential, trilinear, etc., depending upon constitutive equations. The area under the curve is equal to the energy required for separation, i.e., fracture energy G. Those curves give the fracture's approximate behavior. The value of the energy dissipated in the work region is up to the investigated model's shape. The length of the fracture process zone depends on the ratio between a maximum stress and yield stress. An integral part of CZM is the parameters of crack initiation and propagation (Abdel Wahab 2015). Moreover, it allows us to determine the cohesive stresses along the crack propagation path (Ly et al. 2016).

In the present paper, an experimental and numerical analysis of a DCB is conducted to study the propagation conditions. The experimental test is conducted under static conditions with constant velocity. The results show a relation between load and displacement. On the other hand, the computational analysis is conducted to obtain results as accurately as was obtained from the experimental test. The presented approach of using the FEM to determine the value of the critical fracture energy is necessary because of the laminate structure (as the norm method cannot be used in nonsymmetrical specimens).

\section{Materials and methods}

\subsection{Materials, methods and specimen geometry}

Investigated hybrid laminate consists of aluminum alloy AW-6061 T6 as a middle plane (material data in

Table 1 Aluminum alloy AW-6061 T6 properties ("Aerospace Aluminum Distributor Supplier” 2021)

\begin{tabular}{lllll}
\hline & E [MPa $]$ & G $[\mathrm{MPa}]$ & $v$ & $\rho\left[\mathrm{g} / \mathrm{cm}^{3}\right]$ \\
\hline AW 6061 & 70,000 & 26,400 & 0.33 & 2.71 \\
\hline
\end{tabular}

Table 1), and prepreg layers such as Celstran ${ }^{\circledR} C F R$ TP PA6 CF60-01 (60\% of carbon fiber by weight polyamide 6 continuous fiber [unidirectional] reinforced thermoplastic composite tape), and Celstran ${ }^{\circledR}$ CFR-TP PA6 GF60-01 (60\% of E-glass by weight polyamide 6 continuous fiber [unidirectional] reinforced thermoplastic composite tape) (Material data in Table 2). The material disignation is $[3 \mathrm{xCF} / 1 \mathrm{xGF} /$ ALU]s. The sequence of the layers is presented in Fig. 2. Considering this material, its innovative qualities are shown first of all in the matrix material since thermoplastic used as a matrix can increase production capacity because it doesn't need the long-term crosslinking that is required in the case of duroplast materials. Secondly, this material's sequence avoids galvanic cell phenomena due to the placement of glass fiber reinforced plastic layers (dielectric material) along with the aluminum layer.

The manufacturing of the hybrid laminate distinguishes several steps to achieve appropriate stiffness, high strength, and strong adhesive forces between layers. To combine each layer a hot press is processed under defined pressure and temperature. To obtain the greatest adhesive forces as possible the surfaces have to be optimized by an appropriate pretreatment. In the investigated case, the preparation was done on a hot press with a corresponding mold.

Figure 3 gives the pressing process with the appropriate value of pressure and temperature. This process may be divided into three stages:

- heating and plasticizing of the thermoplastic matrix,

- consolidation of the fiber-reinforced thermoplastic,

- cooling and solidifying of the thermoplastic melt.

The highlighted curve shows the required consolidation time.

\subsubsection{Material properties}

Furthermore, the interlaminar section understood as an adhesive layer between the metal and plastic layer shows the properties according to Table 3 .

In the DCB samples, an initial delamination length (a) is determined by a polytetrafluoroethylene strip placed between the metal and fiber layer. The crosssection of the material with layers' thickness is presented in Fig. 4. 
Table 2 Fiber-reinforced plastic layers properties

\begin{tabular}{lllllll}
\hline & $\mathrm{E}_{1}[\mathrm{MPa}]$ & $\mathrm{E}_{2}[\mathrm{MPa}]$ & $v_{12}$ & $\mathrm{G}_{12}[\mathrm{MPa}]$ & $\mathrm{G}_{23}[\mathrm{MPa}]$ & $\mathrm{G}_{13}[\mathrm{MPa}]$ \\
\hline GF60-01 & $49,800.0$ & $18,170.3$ & 0.310 & 2941.2 & 2451.0 & 2451.0 \\
CF60-01 & $139,400.0$ & $17,368.4$ & 0.298 & 3012.0 & 2510.0 & 2510.0 \\
\hline
\end{tabular}

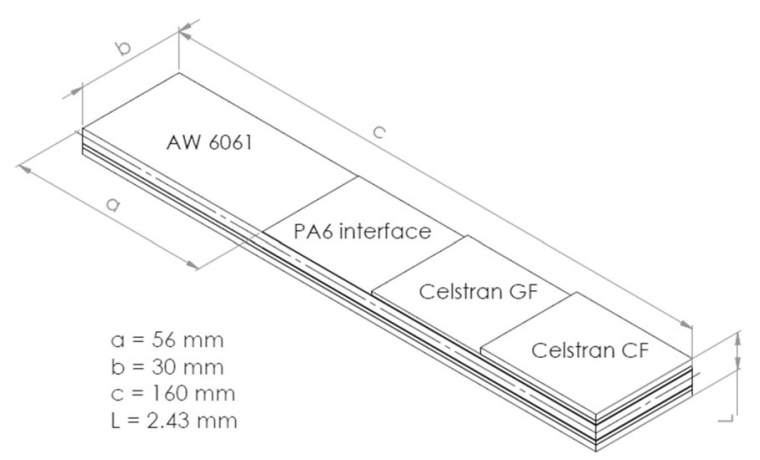

Fig. 2 Schematic representation of specimen geometry

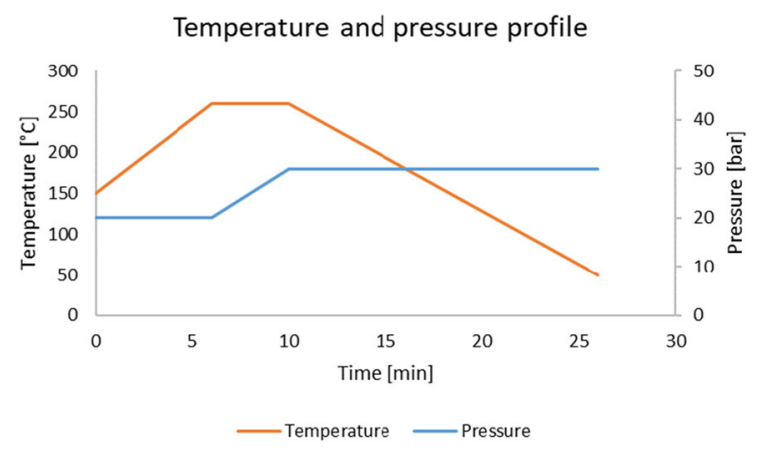

Fig. 3 Temperature and pressure profile of hybrid laminate manufacturing process

Table 3 PA6 interlaminar section properties ("Polyamide Nylon 6-Polyamide 6 (PA6)—Matmatch” 2020)

\begin{tabular}{llll}
\hline & $\mathrm{E}[\mathrm{MPa}]$ & $\mathrm{G}_{1}[\mathrm{MPa}]$ & $\mathrm{G}_{2}[\mathrm{MPa}]$ \\
\hline PA6 & 2700 & 971 & 971 \\
\hline
\end{tabular}

To attach the specimen to the grip, the special loading blocks need to be glued. In the presented case, they were bounded to the specimen using cyanoacrylates adhesive-providing the required strength between carbon fiber reinforced layer and aluminum alloy loading block. After gluing, the samples need to be marked to aid in visual detection of delamination onset. Samples were marked in the first $5 \mathrm{~mm}$ from the insert on edge with thin vertical lines every $1 \mathrm{~mm}$ as is presented in Fig. 5. Moreover, the next $20 \mathrm{~mm}$ were marked with thin vertical lines every $5 \mathrm{~mm}$. The delamination length is the sum of the distance from the point where loading is applied to the end of the insert (measured in the undeformed state) plus the increment of delamination determined from the tick marks.

\subsection{Equipment}

The experiment was conducted using a servohydraulic machine MTS 793 equipped with a $5 \mathrm{kN}$ load cell (Fig. 6). The crosshead speed was around $5 \mathrm{~mm} / \mathrm{min}$. In total, 4 samples were tested, indicated as $C G 1-$ CG4. The procedure of the test followed ASTM standard (ASTM International 2001), and it is divided into two stages. The initial loading is required to obtain the delamination crack growth of 3-5 mm and provides the crack radius theoretically equal to $0 \mathrm{~mm}$ (sharp crack). Finally, the reloading occurs with the same crosshead speed until the specimen crashes.

\subsection{FEM using cohesive elements}

The analysis of the DCB test was performed using ABAQUS. The FEM with cohesive elements was used to approach the delamination growth in a quasi-static regime in the simulation. These elements represent the thin layer between aluminum alloy and glass fiber reinforced layer in the case of this material. Furthermore, the Teflon tape is used as a separator to define the proper way of delamination path. A schematic view of the model is presented in Fig. 7. To describe this phenomenon, the two sets of parameters were applied i.e. propagation parameters based on Benzeggagh-Kenane (BK) law (Benzeggagh and Kenane 1996) that describes mixed-mode according to the Eqs. (1) and crack initiation parameters based on MAXS-maximum stress estimated by the Finite Element Analysis (FEA). 


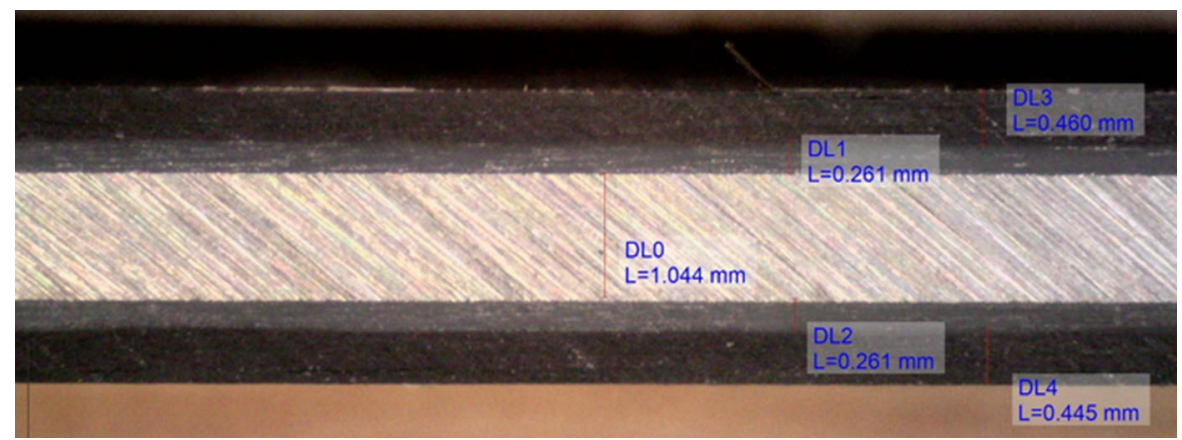

Fig. 4 Longitudinal cross-section of the examined material

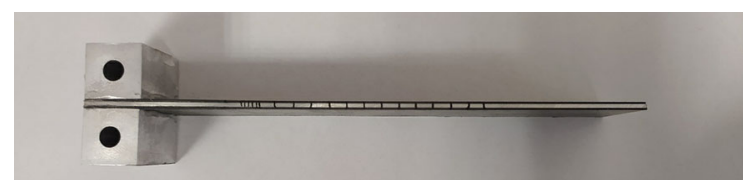

Fig. 5 Prepared specimen with a marked scale

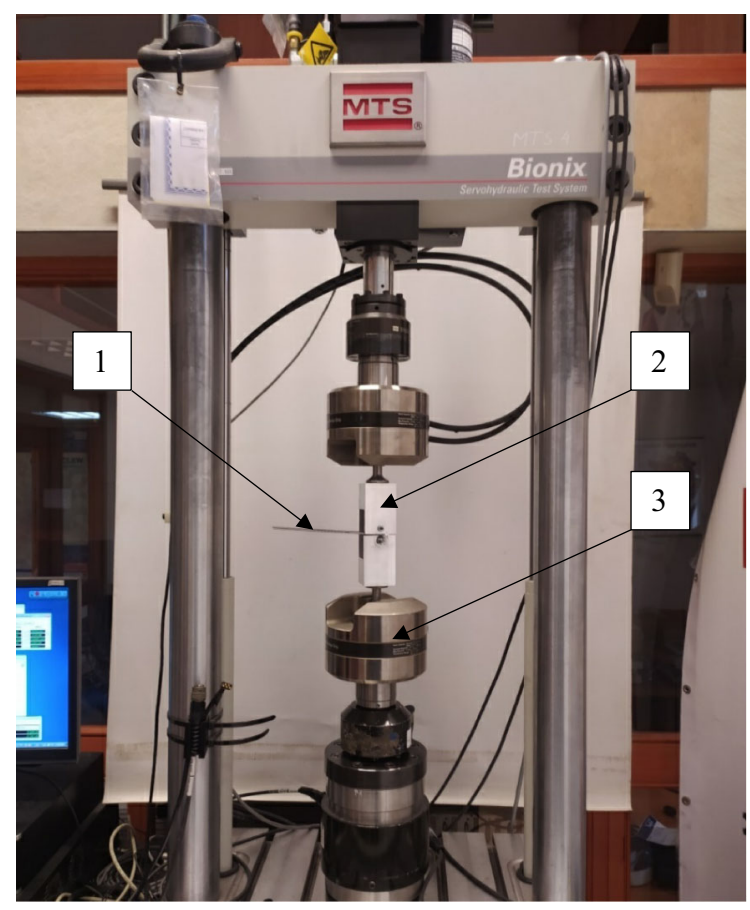

Fig. 6 MTS 793 testing machine with the mounted specimen. Respectively, 1-specimen, 2-clevis, 3-MTS hydraulic grips

$G_{T C}=G_{I C}+\left(G_{I I C}-G_{I C}\right) \cdot\left(\frac{G_{I I}+G_{I I I}}{G_{I}+G_{I I}}\right)^{m}$

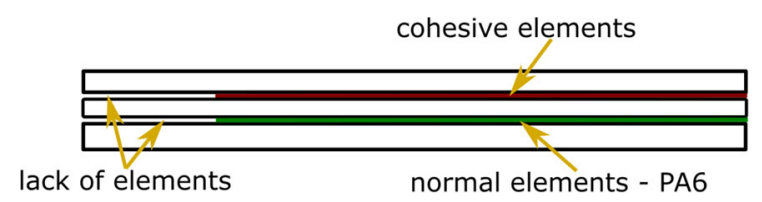

Fig. 7 Schematic description of the model with cohesive elements

where: The exponent $m$ is determined by a curve fit to the fracture toughness, $G_{I}$ is normal mode fracture energy, $G_{I I}$ is shear mode fracture energy first direction, $G_{I I I}$ is shear mode fracture energy second direction, $G_{I c / I I c / I I I c}$ is critical Energy Release Rate associated with the fracture mode I/II/III.

The initial parameters were obtained from the experimental results i.e. from the initial loading stage using the Finite elements (FE) simulation of DCB test. A 5\% Offset/Maximum Load technique (ASTM International 2001) showed the value of the maximum force, which initiates delamination growth (Fig. 8). The displacement at the maximum force was implemented $(46 \mathrm{~mm})$ as the boundary conditions (BC) displacement. The finite model excluding the cohesive zone was generated to obtain the value of the stresses in the required direction (MAXS parameters) (Table 4). Furthermore, Mode I energy's value was correlated from experiment and FEM to obtain the final value. The influence of critical energy in mode II for force-displacement was significantly smaller than for mode I. Thus, further research is needed to investigate this parameter with enough certainty.

The mesomechanical 2D model is considered, which requires implementation of mechanical properties separately for each layer. Table 1 gives properties for the aluminum alloy sheet used as a core (middle sheet) of investigated FML. 
Fig. 8 Results of the initial loading stage
Precrack initiation

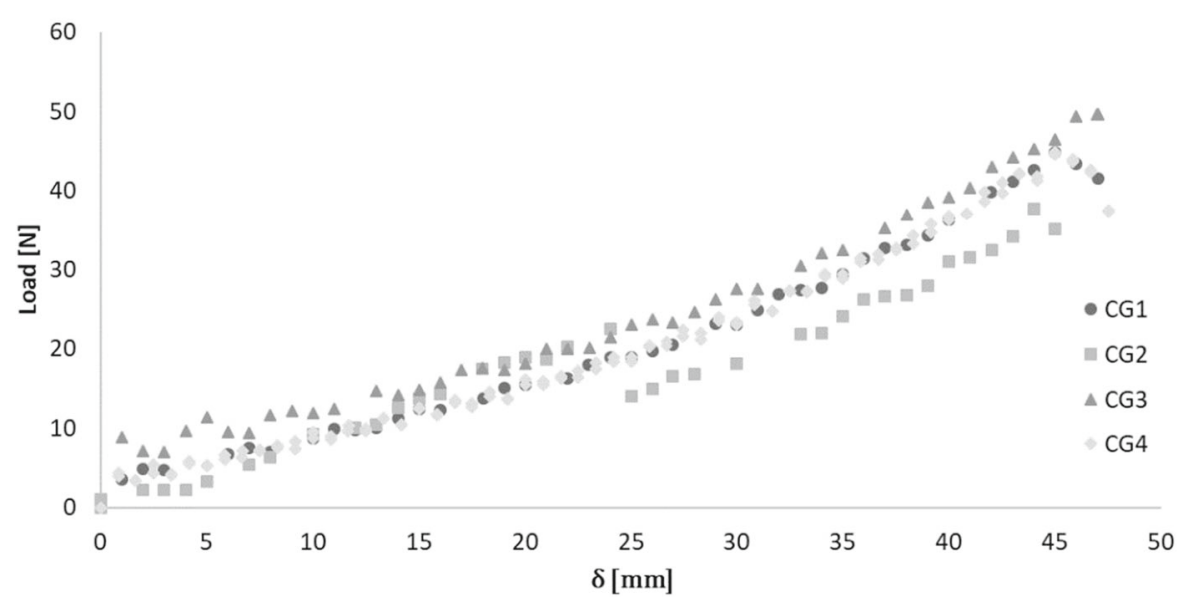

Table 4 Values taken into account while defining the relationship between stresses and opening of the gap for the PA6 interface (MAXS and BK criterion)

\begin{tabular}{llll}
\hline MAXS & Nominal stress normal-only mode & Nominal stress first direction & Nominal stress second direction \\
\hline \multirow{3}{*}{ BK law } & $30 \mathrm{MPa}$ & $2 \mathrm{MPa}$ & $2 \mathrm{MPa}$ \\
& Normal mode fracture & Shear mode fracture energy & Shear mode fracture energy second \\
& energy (mode I) & first direction (mode II) & direction (mode II) \\
& $0.87 \mathrm{~N} / \mathrm{mm}$ & $0.05 \mathrm{~N} / \mathrm{mm}$ & $0.05 \mathrm{~N} / \mathrm{mm}$ \\
\hline
\end{tabular}

Considering the fiber-reinforced plastic layers, two sets of parameters were applied. These parameters were obtained using the eLamX software developed by TU Dresden ("eLamX2-Chair of Aircraft Engineering-TU Dresden" 2020). Moreover, the properties were calculated regarding the Puck failure criteria. The glass-reinforced plastic layer consists of one Celstran ${ }^{\circledR}$ CFR-TP PA6 GF60-01 tape, and the carbon-reinforced plastic layer comprises three (3) Celstran ${ }^{\circledR}$ CFR-TP PA6 CF60-01 tapes. Figure 4 presents the thicknesses of individual layers. The properties from Tables 1, 2 and 3 were implemented in the material models.

The boundary conditions consist of two supports considered in the analysis. One support is locked without rotation UR2 meaning all five DOFs are fixed. The load is created in the way of second support; hence the translation is applied in terms of displacement $(70 \mathrm{~mm})$ logged during the test.

One of the most crucial aspects of delamination using FEA is the finite element size. A certain number of cohesive elements is required to represent the distribution of traction ahead of the crack tip. Thus, a proper choice of mesh size is necessary to obtain accurate FEM results. Several papers (Abdel Wahab 2015; Ly et al. 2016; Panettieri et al. 2016) pointed out this aspect and provide a guideline on how to overcome this issue. Authors such as Panettieri et al. (Panettieri et al. 2016) and Manikandam et al. (Manikandan and Chai 2018) give specific formulas for estimating the cohesive zone length; these approximations influenced the mesh density used in the present paper. The mesh size was estimated as $0.1 \mathrm{~mm}$, providing 22 spatial elements in the cohesive zone.

\subsection{FEM using cohesive surfaces}

For comparison, additional FEA were carried out using a cohesive surfaces approach to model the PA6 film layer. The specimen's geometry in the cohesive surface approach is almost identical to the model 
considered in the cohesive element approach. The only difference is that interface has 0 thickness and is defined by contact properties. A schematic view of the model with the location of contacts and seams are presented in Fig. 9. The constitutive model is based on the traction-separation law, which is the same as in the case of the cohesive element model. In the lower part of the specimen, lack of adhesion is modelled using a seam. In the upper part of the specimen, the contact is defined (with the TSL properties), and the bonding is limited to this length of the specimen which has initial adhesion. The boundary conditions are defined analogically to the previous model. Thus, displacement is defined for the reference point connected with the tab area by using a kinematic coupling. The discrete model was prepared based on the mesh sensitivity study. The results from the mesh sensitivity, which involved various element sizes are presented in Fig. 10. Based on (Hibbit and Sorensen 2013), the accuracy of the cohesive behaviour implementation is dependent on the mesh size of the slave surface in the contact definition. With the slave contact surface defined above, the upper beam lower surface and the mesh were thickened in this area.

\section{Results and discussion}

This section gives the results of the experiment and FEM analysis. Considering the preconditioning stage, the results are presented in Fig. 8, where it should be noted that the maximum force of $46 \mathrm{~N}$ drives the crack initiation and provides a crack length of approximately $50 \mathrm{~mm}$ according to the procedure described in Sect. 6 , the initial parameters were investigated.

The parameters required in the simulation using cohesive elements are shown in Table 4. These parameters were determined by fitting the curves obtained from FEM with the experimental results.

As it is shown the nominal stress that causes the delamination totals $30 \mathrm{MPa}$, there may also be a small

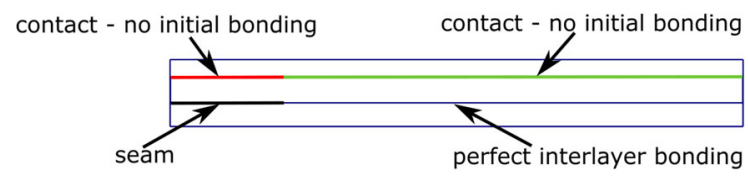

Fig. 9 Schematic description of the model with cohesive surfaces influence of shear stresses in the interlaminar cohesive layer. The value of fracture energy for mode I is estimated at $0.87 \mathrm{~N} / \mathrm{mm}$, which is in the range between the epoxy resin and PEEK material according to the data included in the ASTM D5528-01 (ASTM International 2001). Moreover, the crack initiation stress parameters provide a proper initiation time of the delamination growth.

The process of the reaction force versus displacement presented in Fig. 11 proves the correctness of this value. Looking at the results, the initiation (displacement) of the delamination occurred in a proper time which is shown as the curves plummeted after $50 \mathrm{~mm}$. Both cohesive element approach and cohesive surfaces approach give similar maximum force and displacement at maximum forces as the experiments. However, the model based on cohesive elements has a more similar shape of force-displacement curve (results are presented in Table 5). It is probably the effect of the non-zero thickness layer of PA6 in the cohesive element model, which was not included in simpler cohesive surfaces models.

The sample deformation in the experiment may suggest that there is small participation of mode II. To show that founded parameters and global stiffness of the sample are correct, Fig. 12 presents the deformation of the sample in reference to sample angle $(\theta)$. As it is shown, the global trends to deformation of the finite model and real objects are similar. It suggests that the results are perhaps not accurate, but they may be in an acceptable range.

Below in Table 5 comparison of maximum force (and displacement in this moment) between experiment and numerical simulations is presented.

\section{Conclusions}

In the study, the mode I was analyzed for innovative hybrid laminate. The research provides data from the experiment and FEM analysis. Considering FEA, the cohesive zone elements' application yield content results considering the energetic parameters of the fracture toughness. This solution determines the fracture toughness, including each mode for the materials with different layers such as inverse FML, which the standardized formulas included in the ASTM standard do not cover. Moreover, CZM permits 
Fig. 10 Mesh sensitivity study for cohesive element model

Fig. 11 Results from the DCB tests and numerical modelling

\section{Mesh sensitivity}

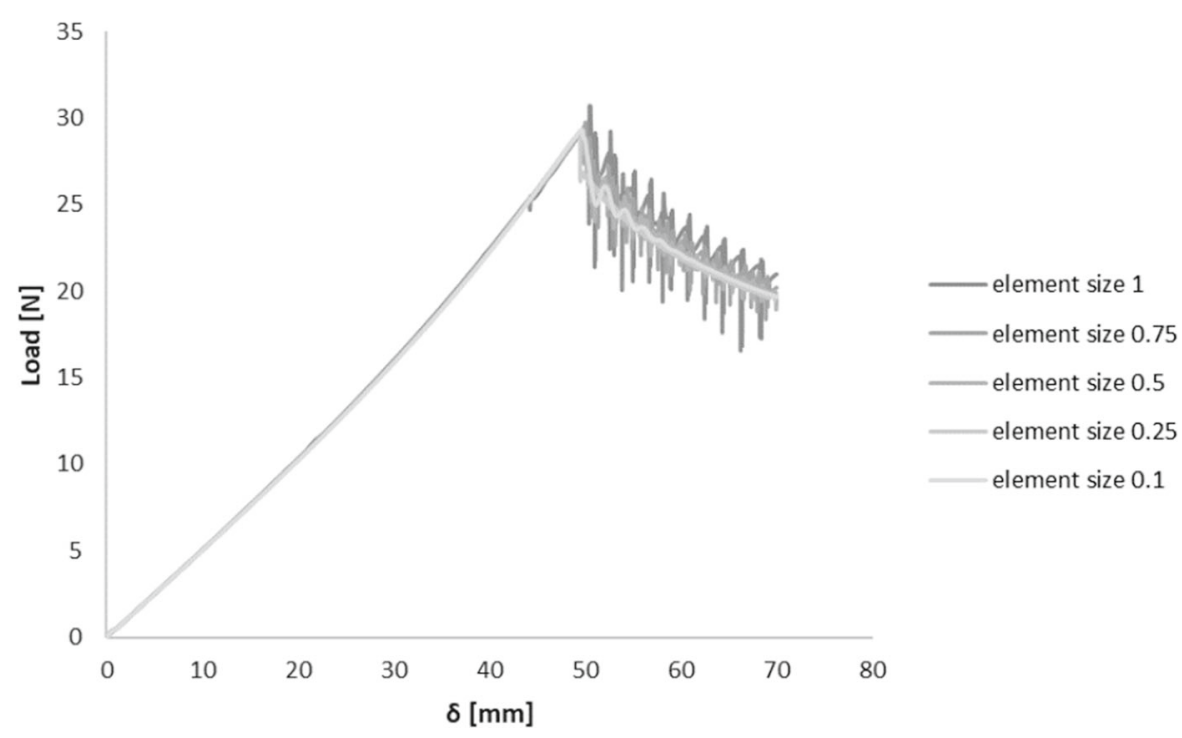

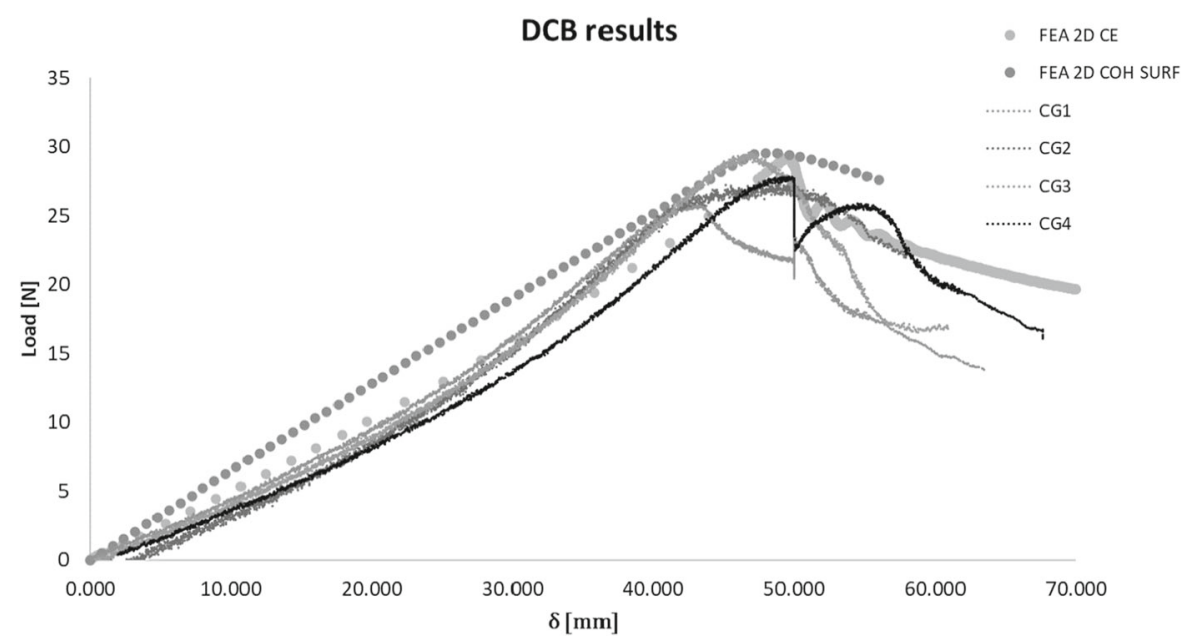

Table 5 Maximum force values in DCB test for experimental campaign and FEM models with cohesive elements (CE) and cohesive surfaces (CS)

\begin{tabular}{lllllll}
\hline & CG1 & CG2 & CG3 & CG4 & FEM (CE) & FEM (CS) \\
\hline Max force [N] & 27.06 & 29.26 & 31.10 & 33.06 & 29.32 & 29.55 \\
Displacement at max force [mm] & 49.47 & 48.60 & 42.60 & 49.47 & 49.64 & 48.00 \\
\hline
\end{tabular}

investigation of the fundamental causes of failure of these laminates.

The following conclusions are drawn:
- The initial stress parameters were obtained using the preconditioning data from the DCB test, the nominal stress that is the most relevant totals $30 \mathrm{MPa}$ which is a reasonable value considering the stiffness of PA6 and width of this layer, 
(a)

(b)

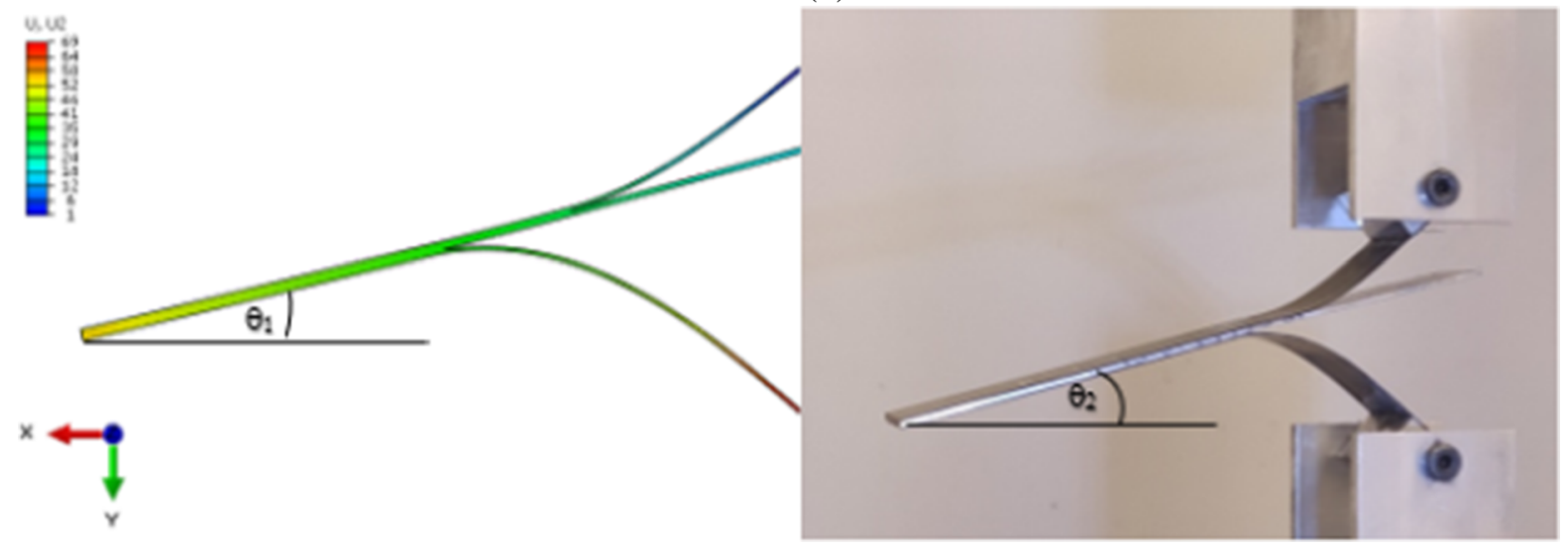

Fig. 12 A comparison of sample angle $(\theta)$ obtained from FEA (a) and the experiment (b)

- The FEM analysis lets us determine the value of the interlaminar fracture energy $\left(\mathrm{G}_{\mathrm{Ic}}\right)-0.87 \mathrm{~N} /$ $\mathrm{mm}$. Due to this value, the process of delamination can be further investigated using FEA in the design stage and in larger structures.

- In the paper two approaches were used for modelling the DCB test cohesive elements and cohesive surfaces. Both of these approaches led to nearly the same value of the maximum force and displacement (when the maximum force is exerted). However, simulation based on cohesive elements in the case of conducted test has a more similar shape of the force-displacement curve to experimental results.

- Further work may involve the investigation of the Mode II and Mode III fracture energy for these materials. It would allow conducting the comprehensive FEM analysis of structures made from these laminates,

- The approach presented in this paper can be used to determine the value of fracture energy and damage initiation stress for this kind of material. Determining such parameters makes it possible to model structures, including the analysis of the interfaces in such laminates.

Acknowledgements Calculations have been carried out using resources provided by Wroclaw Centre for Networking and Supercomputing (http://wcss.pl), Grant No. 531.

Open Access This article is licensed under a Creative Commons Attribution 4.0 International License, which permits use, sharing, adaptation, distribution and reproduction in any medium or format, as long as you give appropriate credit to the original author(s) and the source, provide a link to the Creative Commons licence, and indicate if changes were made. The images or other third party material in this article are included in the article's Creative Commons licence, unless indicated otherwise in a credit line to the material. If material is not included in the article's Creative Commons licence and your intended use is not permitted by statutory regulation or exceeds the permitted use, you will need to obtain permission directly from the copyright holder. To view a copy of this licence, visit http://creativecommons.org/licenses/by/4.0/.

\section{References}

Abdel Wahab MM (2015) "Simulating mode I fatigue crack propagation in adhesively-bonded composite joints." Fatigue and fracture of adhesively-bonded composite joints. Elsevier, Amsterdam, pp 323-344

“Aerospace Aluminum Distributor Supplier”. [Online]. Dostępne na: https://www.aerospacemetals.com/aluminumdistributor.html\#tech. Udostępniono 20 maj 2021

Aksit M, Altstädt V (2020) Hybrid materials-historical perspective and current trends. COJ Rev Res 2(3). https://doi. org/10.31031/COJRR.2020.02.000539

Alfano G, Crisfield MA (2001) Finite element interface models for the delamination analysis of laminated composites: mechanical and computational issues. Int J Numer Methods Eng 50(7):1701-1736

Alfano M, Furgiuele F, Leonardi A, Maletta C, Paulino GH (2007) Cohesive zone modeling of mode I fracture in adhesive bonded joints. Key Eng Mater 348-349:13-16

ASTM International (2001) D5528-01 standard test method for mode I interlaminar fracture toughness of unidirectional fiber-reinforced polymer matrix composites. ASTM International, West Conshohocken, PA. https://doi.org/10. 1520/D5528-01 
Balkumar K, Iyer AV, Ramasubramanian A, Devarajan K, Marimuthu PK (2016) Numerical Simulation of Low Velocity Impact Analysis of Fiber Metal Laminates.

Banat D, Kolakowski Z, Mania RJ (2016) Investigations of fml profile buckling and post-buckling behaviour under axial compression. Thin-Walled Struct 107:335-344

Benzeggagh ML, Kenane M (1996) Measurement of mixedmode delamination fracture toughness of unidirectional glass/epoxy composites with mixed-mode bending apparatus. Compos Sci Technol 56(4):439-449

Bieniaś J, Dadej K, Surowska B (2017) Interlaminar fracture toughness of glass and carbon reinforced multidirectional fiber metal laminates. Eng Fract Mech 175:127-145

Botelho EC, Silva RA, Pardini LC, Rezende MC (2006) A review on the development and properties of continuous fiber/epoxy/aluminum hybrid composites for aircraft structures. Mater Res 9(3):247-256 (Universidade Federal de Sao Carlos)

Burlayenko VN, Sadowski T (2008) FE modeling of delamination growth in interlaminar fracture specimens. Bud Arch 2(1):095

Carrillo JG, Cantwell WJ (2009) Mechanical properties of a novel fiber-metal laminate based on a polypropylene composite. Mech Mater 41(7):828-838

Diehl T (2005) Modeling surface-bonded structures with Abaqus cohesive elements: beam-type solutions. Abaqus User's Conference

Ding Z, Wang H, Luo J, Li N (2021) A review on forming technologies of fibre metal laminates. Int $\mathrm{J}$ Light Mater Manuf 4(1):110-126

"eLamX ${ }^{2}$ - Chair of Aircraft Engineering-TU Dresden". [Online]. Dostępne na: https://tu-dresden.de/ing/ maschinenwesen/ilr/lft/elamx2/elamx?set_language=en. Udostępniono 03 lis 2020

Elices M, Guinea GV, Omez JG, Planas J (2002) The cohesive zone model: advantages, limitations and challenges. Eng Fract Mech 69(2):137-163

Goyal V, Irizarry V (2016) Development of a Combined Cohesive and Extended Finite Element Method to Predict Delamination in Composite Structures, w 57th AIAA/ ASCE/AHS/ASC Structures, Structural Dynamics, and Materials Conference.

Hibbit, Karlsson, i Sorensen (2013) Surface-based cohesive behavior, Abaqus Anal. User's Guid, ss. 37.1.10-1-19.
Jimenez MA, Miravete A (2004) Application of the finite-element method to predict the onset of delamination growth. J Compos Mater 38(15):1309-1335

Ly R, Jumel J, Shanahan MER, Lavelle F (2016) Cohesive zone model identification with dcb test parameter estimation sensitivity, ECCOMAS Congress 2016-Proceedings of the 7th European Congress on Computational Methods in Applied Sciences and Engineering, 2: 3676-3688.

Manikandan P, Chai GB (2018) Mode-I metal-composite interface fracture testing for fibre metal laminates. Adv Mater Sci Eng 2018:1-11

Millar TM, Williams JG, Balint DS (2014) The cohesive zone model applied to blunt cracks. Procedia Mater Sci 3:313-317

Ning $\mathrm{H}$ et al (2015) Experimental and numerical study on the improvement of interlaminar mechanical properties of Al/ CFRP laminates. J Mater Process Technol 216:79-88

Osiecki $\mathrm{T}$ et al (2020) Inverse hybrid laminate for lightweight applications. Key Eng Mater 847:40-45

Panettieri E, Fanteria D, Danzi F (2016) A sensitivity study on cohesive elements parameters: towards their effective use to predict delaminations in low-velocity impacts on composites. Compos Struct 137:130-139

"Polyamide Nylon 6-Polyamide 6 (PA6)-Matmatch". [Online]. Dostępne na: https://matmatch.com/materials/ good00049-polyamide-nylon-6. Udostępniono 03 lis 2020

Salve A, Kulkarni R, Mache A (2016) A review: Fiber Metal Laminates (FML's) - manufacturing, test methods and numerical modeling. Int J Eng Technol Sci 6(1):71-84

Soroush M, Malekzadeh Fard K, Shahravi M (2018) Finite element simulation of interlaminar and intralaminar damage in laminated composite plates subjected to impact. Lat Am J Solids Struct. https://doi.org/10.1590/167978254609

Tomasz O, Colin G, Hackert A, Timmel T, Lothar K (2017) High-performance fiber reinforced polymer/metal-hybrids for structural lightweight design. Key Eng Mater 744:311-316

Publisher's Note Springer Nature remains neutral with regard to jurisdictional claims in published maps and institutional affiliations. 